\title{
A cut e o sindicalismo brasileiro nos anos recentes Limites e possibilidades ${ }^{1}$
}

Mario Henrique Guedes Ladosky e Iram Jácome Rodrigues

Introdução

As experiências subjetivas compartilhadas pelos trabalhadores no período do regime militar, com a exacerbação do autoritarismo nos locais de trabalho e o silêncio imposto às organizações sindicais enquanto ampliava-se a acumulação das grandes empresas nos meios urbano e rural, constituíram a base que nutriu o recrudescimento das lutas sindicais e populares no final dos anos de 1970, com a explosão de greves em inúmeras categorias, e da qual frutificaram instituições - o Partido dos Trabalhadores (Рт), a Central Única dos Trabalhadores (CUT) e o Movimento dos Sem Terra (MST) - que disputaram a construção de um projeto de nação baseado na democracia, na inclusão e direitos sociais, entre outros aspectos. Não era apenas uma questão econômica de recomposição das perdas salariais sofridas. Estava em questão o resgate da dignidade (Abramo, 1999) e a demanda por direitos de cidadania (Rodrigues, 2011). Pouco mais de vinte anos depois, com todas as vicissitudes das lutas sociais, Lula chegou à presidência da República representando aquele projeto, abrindo novas possibilidades de avanços sociais e desafios inéditos ao sindicalismo e à CUT diante de tal perspectiva. Ao final da experiência do PT à frente do governo federal, em 2016, em que medida esse sindicalismo logrou êxito em seu papel? Que questões ressurgem para o sindicalismo diante do legado dos governos Lula e Dilma? Este texto analisará alguns aspectos dessa trajetória.

1. Resultados parciais de projeto de pesquisa em andamento apoiado pelo CNPq. 
O sindicalismo brasileiro viveu uma inflexão em sua trajetória nos anos de 1990 quando comparado com o momento de recrudescimento das lutas sindicais no final dos anos de 1970 e até meados da década de 1980, com elevado número de greves e padrão altamente conflitivo na relação capital/trabalho (Noronha, 1991).

A Central Única dos Trabalhadores (CUT), que havia se notabilizado pelas mobilizações e greves teve, nesse novo contexto, um forte revés na sua ação sindical o que levou a uma significativa mudança na sua estratégia. Deixou de se apoiar em uma concepção mais “movimentista”, de estreita relação com os movimentos sociais e privilegiou a instituição ${ }^{2}$. Vale dizer, passou de uma CUT - movimento para uma CUT -organização, em que o peso dos sindicatos na representação institucional se mostrou mais forte que a via de confronto do período anterior (Rodrigues, 2011; Ladosky, 2009).

O maior exemplo dessa mudança ocorreu em 1992 e 1993, quando o sindicato mais importante da base da CUT, o Sindicato dos Metalúrgicos do ABC, decidiu participar das rodadas de negociação da Câmara Setorial do setor automotivo, um espaço tripartite de concertação.

Da mesma forma, naquele momento, a CUT passou a defender uma visão que os sindicalistas chamaram de "sindicalismo-cidadão", assumindo espaços de representação da classe para além do mundo do trabalho (Véras de Oliveira, 2011), comprometendo-se com a elaboração de políticas públicas em áreas como saúde, direitos da criança e do adolescente, assistência social etc. Nessa linha de ação, também desenvolveu, na ocasião, uma atuação prática na qualificação profissional e na intermediação de mão de obra de trabalhadores (para empregados e desempregados) financiada com recursos públicos do Ministério do Trabalho através do Planfor Plano Nacional de Qualificação do Trabalhador -, na gestão de FHC. Nesse aspecto, o slogan da CUT, nos anos de 1990, passou a ser o de uma "resistência propositiva".

As novas práticas incorporadas pela CUT levavam em conta também as mudanças no cenário sindical, com a criação da Força Sindical ${ }^{3}$ (FS), em 1991, como uma central oponente à CUT e à altura de disputar com esta a posição hegemônica no sindicalismo brasileiro.

2. A mudança na estratégia política da CUT, em converter-se de um "movimento" para uma "instituição sindical”, teve início no $3^{\circ}$ Congresso Nacional da CUT ( $3^{\circ}$ Concut), em 1988, através de alterações estatutárias que deram ênfase à participação nas instâncias de deliberação para entidades sindicais (não mais de oposições sindicais), a dirigentes com cargos nas entidades (diminuindo a participação de trabalhadores de base) e ao número de delegados em razão da sindicalização (não mais ao tamanho das categorias). Para além das resoluções de ordem estatutária, firmou-se a partir do $3^{\circ}$ Concut a concepção sindical quanto ao papel de representação, negociação e contratação coletiva, a fim de assegurar conquistas de direitos aos trabalhadores.

3. Ver, entre outros, Rodrigues e Cardoso (1993), Trópia (2009). 
Independentemente das posturas dessas duas centrais sindicais e da posição contrária ou favorável às medidas neoliberais no período, ocorreu uma significativa mudança no perfil dos trabalhadores, sobretudo naqueles setores mais dinâmicos da economia.

O corte geracional entre os trabalhadores durante a década de 1990 se refletiu na combinação de um movimento político nacional em torno da concepção neoliberal com a dinâmica da reestruturação capitalista global, cujos efeitos sobre as classes trabalhadoras e o sindicalismo se faz presente até os dias atuais.

Nesse sentido, o conjunto das inflexões vividas no país, nesse período, constituiu a base sobre a qual o sindicalismo atuou neste início de século XXI e cuja novidade foi a eleição de Lula à presidência da República trazendo desdobramentos significativos à ação sindical.

Este artigo tem como objetivo discutir o processo em que se deu a ação do sindicalismo brasileiro e, em especial, da Central Única dos Trabalhadores, no período dos governos Lula e Dilma, tomando como base os anos de 2003 a 2015, levando em conta alguns momentos da atuação sindical em nosso país. $\mathrm{O}$ nosso argumento é que uma parcela significativa do sindicalismo e, em particular, a CUT, diante das novas condições vividas pelo Brasil, naquele momento, optou por uma atuação mais institucional em contraposição a uma ação que contemplasse maior mobilização dos trabalhadores na defesa de suas demandas e, principalmente, deixou de lado uma atividade mais voltada à organização dos trabalhadores nos locais de trabalhó. É possível que esse deslocamento da ação sindical da CUT tenha sido responsável por uma "perda do protagonismo nas ruas" e, talvez, seja parte da explicação para a insuficiente resistência - até o momento - do sindicalismo ao desmonte dos direitos ${ }^{6}$ que está sendo levado adiante pelo governo Temer.

4. Para Galvão e Marcelino (2017, p. 2) “a proximidade entre a cúpula do movimento sindical e o governo inibiu o confronto sistemático dos interesses das organizações sindicais e dos trabalhadores por elas representados", levando a uma moderação da luta política.

5. A discussão sobre "perda de protagonismo das ruas" emerge no contexto das jornadas de junho de 2013 quando milhares de pessoas saíram às ruas, nas principais cidades do país, em protesto contra uma miríade de questões como preço de passagens de transporte público urbano, saúde, educação, corrupção etc. As análises sobre o significado daquelas manifestações são as mais variadas. A intenção deste artigo não é discutir esse tema, apenas chamar a atenção para o contraste entre a quantidade de pessoas mobilizadas naqueles atos com as manifestações sindicais da mesma época, com um número bem menor de militantes em torno das questões do trabalho. Segundo Cardoso (2014, p. 126), o Dia Nacional de Luta do sindicalismo, realizado em 11/7/2013, "levou mais de 100 mil pessoas às ruas em mais de 100 cidades [...] números expressivos, embora eclipsados pelas jornadas de junho, que tinham levado às ruas mais de 1 milhão de pessoas". Ver também sobre esta questão, (Braga e Santana, 2015).

6. As centrais sindicais resistiram como puderam à reforma trabalhista apoiada pelo governo Temer e encaminhada ao Congresso Nacional. No dia 28 de abril de 2017 a greve geral convocada pelas entidades sindicais, com apoio da Frente Brasil Popular e da Frente Povo Sem Medo, foi considerada a 
Alcances e limites da ação sindical institucionalizada

Singer (2012), analisando o governo Lula, observa que este carregou a marca da contradição entre "reforma gradual e pacto conservador". Segundo o autor, o presidente Lula teria promovido um "reformismo fraco", isto é, mudanças profundas em um ritmo lento o suficiente para não acirrar o conflito com a classe dominante. Tendo colocado, em um primeiro momento, o centro da ação do Estado no combate à fome e à miséria, o governo teria logrado um realinhamento eleitoral, conquistando as camadas mais pobres da população para sua base política. Teria havido, assim, uma nova polarização política, em que o foco do conflito estaria situado entre pobres e ricos, preservando e até ampliando os ganhos do capital, porém orientado para a justiça social ${ }^{7}$.

Em termos de plataforma econômica, o governo Lula incorporou e combinou três agendas contraditórias, para compatibilizar os diversos interesses de classes. Por um lado, manteve parte das políticas de seu antecessor - o tripé macroeconômico do superávit primário, câmbio flutuante e metas de inflação - na "Carta aos brasileiros", ainda durante a campanha eleitoral de 2002. A adoção de tais medidas em seu primeiro ano de governo, junto com a reforma da previdência no setor público, causou enorme impacto político no campo da esquerda e no meio sindical, sobretudo à CUT (Ladosky, 2009), que passou por cisões levando ao surgimento da CsP-Conlutas e a Intersindical, numa crítica à postura passiva da direção da CUT diante do governo ${ }^{8}$. Por outro lado, a partir de 2005, retomado o controle da situação econômica, e contando com os bons ventos da economia internacional, o governo Lula assumiu

maior da história brasileira pelas entidades organizadoras. Na ocasião, ocorreram paralisações no setor de transportes nas principais capitais, em fábricas, bancos, comércio, repartições públicas, bloqueio de rodovias em todo o país etc. Ver, por exemplo, jornais El País, Folha, O Globo de 29/4/2017. No dia 24 de maio de 2017, cerca de um mês após aquela manifestação, as centrais sindicais, junto com outros movimentos sociais, realizaram a 9 ${ }^{a}$ Marcha, também convocada como “Ocupa Brasília”, reivindicando "Eleições Diretas Já” e contra as reformas propostas por Temer. De acordo com a imprensa alternativa, concentraram-se 200 mil manifestantes na Esplanada dos Ministérios, duramente reprimidos pela Polícia Militar do DF. A nova paralisação das centrais, convocadas para dia 30 de junho de 2017 não conseguiu a mesma repercussão pública, conforme as próprias entidades. Apesar das lutas encaminhadas pelas centrais sindicais, em 11 de julho de 2017 o Senado aprovou a reforma trabalhista com cinquenta votos favoráveis ao projeto de lei da câmara (PLC) 38/2017 (26 senadores contrários e uma abstenção). A proposta de emenda à constituição (PEC) 287/2016, sobre a reforma da previdência, ainda tramita no Congresso Nacional.

7. Para uma discussão mais ampla das relações entre sindicato e política, governos trabalhistas e sindicalismo e das vicissitudes da ação sindical e Estado ver, por exemplo, Rodrigues (1999), Hyman e Gumbrell-McCormick (2010), Hyman (2001), Gumbrell-McCormick e Hyman (2013).

8. Para uma discussão desse período ver, entre outros, Fortes e French (2012) e Véras de Oliveira, Bridi e Ferraz (2014). 
outras duas agendas na política econômica. Uma, com caráter neodesenvolvimentista (Boito Jr, 2012), levou ao redirecionamento da ação estatal via investimentos públicos em obras de infraestrutura e programas sociais, induzindo os investimentos da iniciativa privada. O Programa de Aceleração do Crescimento (PAC) com seus vários desdobramentos é o principal exemplo dessa agenda. Finalmente, a agenda econômica se completa com medidas de inclusão dos segmentos sociais mais vulneráveis através de programas como o Bolsa Família, assim como outras iniciativas que desempenharam um papel importante na ativação do desenvolvimento local, tanto pelo aumento do consumo das famílias, quanto pelo incentivo a empreendimentos de economia solidária, sobretudo na agricultura familiar que foi estimulada por vários programas do Ministério do Desenvolvimento Agrário (MDA) de financiamento a baixo custo para o pequeno agricultor e pela compra dos produtos da agricultura familiar pelo Estado, entre outros.

A política econômica do governo do PT que foi ao encontro das bandeiras históricas do sindicalismo CUT, do ponto de vista mais corporativo (emprego e salário), foi a de segundo tipo. Do ponto de vista do projeto solidário e emancipatório de sociedade, a coesão entre governo petista e CUT coadunou-se em torno da terceira agenda voltada aos mais pobres, embora esta acrescentasse pouco em termos de ampliação da representatividade do sindicalismo em geral, com exceção do sindicalismo rural ligado à agricultura familiar.

No equilíbrio entre "reforma e conservação" e a compatibilização de diversos interesses em meio a essas agendas "contraditórias" de política econômica, Gustavo Codas, antigo assessor sindical da CUT que esteve presente no PT e no governo, disse: "Creio que o sindicalismo desempenhou um papel praticamente nulo durante os governos de Lula. Minha percepção é que Lula já sabia que os sindicatos podiam 'se cuidar sozinhos' e que onde mais se necessitava a presença do Estado e do governo era nos setores mais pobres, menos organizados e, em termos regionais, no Nordeste". (Codas, apud Dobrusin, 2017, p. 201).

Nesse processo, os trabalhadores formais do mercado de trabalho tiveram, de modo geral, e sob o patrocínio do sindicalismo, ganhos salariais expressivos. A valorização do salário mínimo, no período 2003-2015, segundo dados do IBGE, resultou em aumento real de $77 \%$. De outra parte, o ambiente econômico favorável, o aumento do emprego formal e a estabilidade política permitiram aos sindicatos de trabalhadores do setor privado (indústria, comércio e serviços) a conquista de ganhos reais de salário (acima da inflação) nas Convenções Coletivas (Dieese, 2016).

O Gráfico 1, referente ao período 2003 a 2015, por exemplo, chama a atenção pelo fato que, à exceção do ano de 2003, em todos os outros anos do período os trabalhadores tiveram percentual de reajuste dos salários nas convenções coletivas 


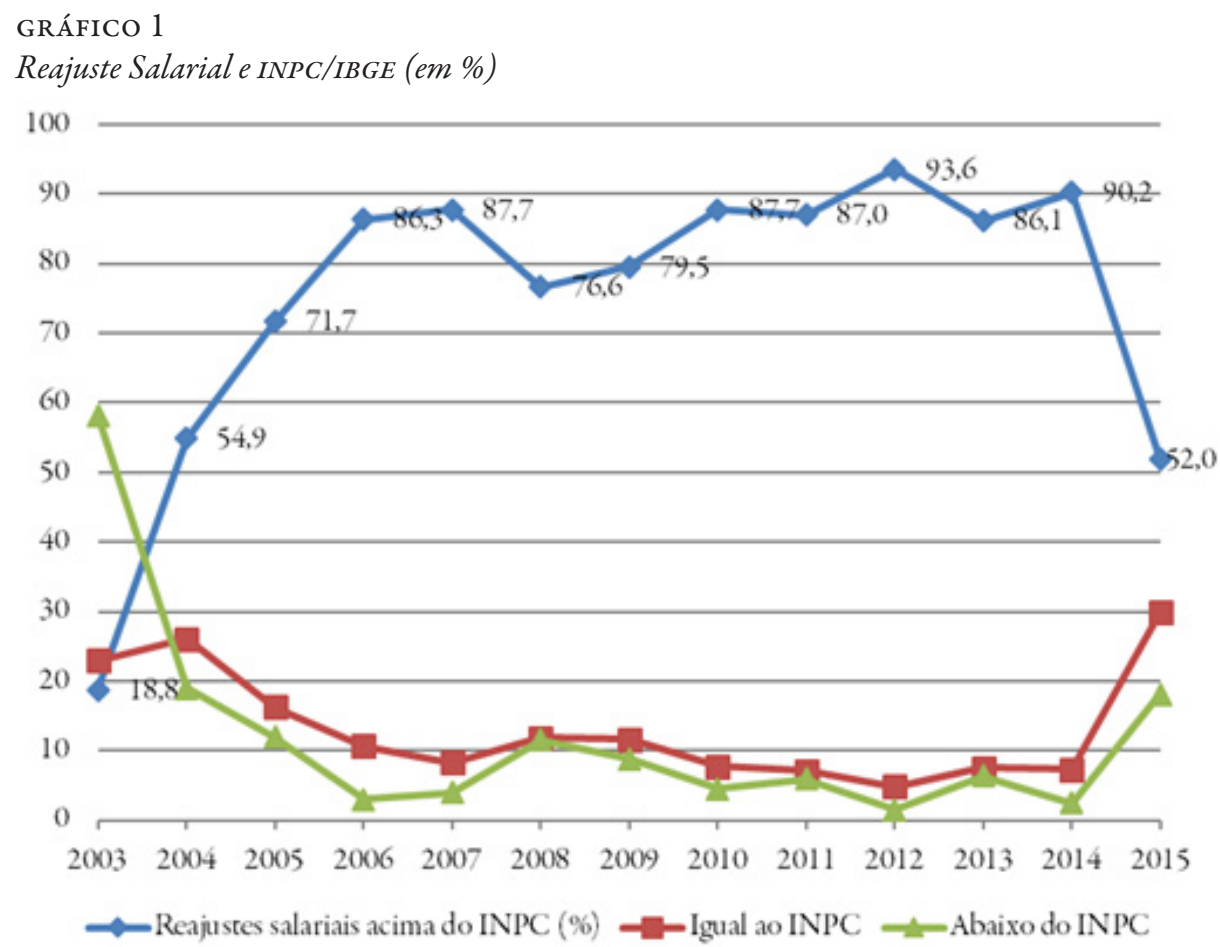

Fonte: Dieese. Sistema de Acompanhamento de Salários (sAS/ Dieese), 2016.

acima do INPC/IBGE. Afora os anos de 2004 e 2015, quando um pouco mais de $50 \%$ dos acordos salariais estiveram acima da inflação, em todos os outros anos do período mais de $70 \%$ das negociações alcançaram resultados acima da inflação e nos anos 2012 e 2014 mais de 90\% das referidas "unidades de negociação" (Dieese) estiveram acima do INPC/IBGE9 .

Os trabalhadores rurais, como assinalado anteriormente, também tiveram melhorias em seus ganhos nesse período, sobretudo em decorrência das políticas públicas executadas pelo Ministério do Desenvolvimento Agrário (MDA) para o segmento da agricultura familiar.

No que tange à Central de Trabalhadores e Trabalhadoras do Brasil (Ств), оs resultados positivos do governo na área social e do desenvolvimento, com geração de emprego e renda, legitimaram suas posições políticas de apoio. Mesmo a Força Sindical, a Central Geral dos Trabalhadores do Brasil (сGтв) e a Nova Central Sindical dos Trabalhadores (NCST) - centrais sindicais ${ }^{10}$ muitas vezes oposicionistas ao

9. "Por unidade de negociação, entende-se cada núcleo de negociação coletiva entre representantes de trabalhadores e empresários que resulta em um ou mais documentos formalizados entre as partes, nos quais são estabelecidas normas para a regulamentação do trabalho" (Dieese, 2016). Atualmente, são analisadas cerca de setecentas unidades de negociação.

10. Sobre as novas centrais sindicais no Brasil e suas bases sociais, ver, Galvão, Marcelino e Trópia (2015). 
governo do PT -aliaram-se em torno da candidatura de Dilma Roussef na eleição de 2010, participando da Assembleia da Conferência Nacional da Classe Trabalhadora, em junho daquele ano.

No entanto, os resultados positivos das políticas públicas e os aumentos salariais nas Convenções Coletivas de Trabalho coexistiram com níveis de precariedade no mercado de trabalho, com a manutenção de elevado nível de rotatividade, de atividades terceirizadas e ampliação de tipos de contratação flexíveis (Krein et al., 2012; Ladosky et al., 2014).

Da mesma forma, os avanços obtidos pelos trabalhadores rurais da agricultura familiar não foram acompanhados por uma política agrária que propiciasse acesso à terra (Umbelino apud Ramos, 2011).

De outra parte, os servidores públicos foram os trabalhadores que tiveram maior dificuldade em obter conquistas em qualquer um dos níveis do Estado: municipal, estadual e federal. A continuidade da lógica de ajuste fiscal, por exemplo, com a vigência da Lei de Responsabilidade Fiscal (LRF), manteve fortes restrições orçamentárias, trazendo impactos não apenas no salário, mas também nas condições de trabalho. Por essa razão, ampliaram-se os tipos de contratação no serviço público, desde a terceirização de atividades por empresas privadas, contratação de estagiários, contratação por tempo determinado (contratos de emergência, contrato de substitutos etc.) até a transferência de gestão de equipamentos e de funcionários para Organizações da Sociedade Civil de Interesse Público (oscıp’s). Para Nogueira,

[...] o legado do governo FHC sob o manto da modernidade do Estado e da adoção de padrões gerenciais para a função pública não encontrou contraponto e nem qualquer alternativa efetiva na passagem para o governo Lula. A inovação apresentada diz respeito à criação das mesas permanentes de negociação que poderia abrir novas perspectivas nas relações de trabalho. No entanto, a política macroeconômica truncou os avanços que o governo Lula poderia apresentar na esfera pública. Há um discurso de mudança, mas, na prática, há a conservação e recorrência das deficiências anteriores (2006, p. 16).

A não regulamentação da lei que ratificou a Convenção 151 da Organização Internacional do Trabalho (OIT) ${ }^{11}$ privou os sindicatos do setor público de um

11. A Convenção 151 da OIT foi aprovada em 1978 e dispõe sobre as relações de trabalho na Administração Pública, normatizando temas como negociação coletiva e sindicalização no setor público. No Brasil, a Convenção foi ratificada através de aprovação do decreto legislativo n· 206, em 7 de abril de 2010, e sancionada pelo presidente Lula em 15 de junho 2010. Até o presente momento a Convenção 151 não foi regulamentada em uma legislação nacional. Disponível em: http://www.oitbrasil.org.br/ node/501. Acesso em: 12/8/2017. 
espaço de negociação coletiva institucionalizado. Assim, se o sindicalismo obteve alguns ganhos significativos nos governos Lula e Dilma, questões importantes do mundo do trabalho permaneceram inalteradas em seu grau de precariedade e, além disso, grande parte das demandas do movimento sindical sequer foi levada adiante como, por exemplo, a redução da jornada de trabalho para 40 horas semanais sem redução salarial, ratificação da Convenção 158 da OIT $^{12}$ e o fim das terceirizações.

Se, conforme Singer (2012), o "reformismo fraco" voltou-se prioritariamente para a erradicação da fome e da miséria no país, atuando no terreno em que a exclusão social é mais aguda e impede os avanços básicos dos direitos de cidadania, coube ao movimento sindical representante dos trabalhadores incluídos no mercado de trabalho lograr suas conquistas através do ambiente mais favorável à negociação coletiva, conforme sublinhado anteriormente.

Por outro lado, o êxito na disputa por um projeto de sociedade socialmente justo, para além das conquistas da negociação coletiva das categorias assalariadas, requeria do sindicalismo uma ação no campo institucional rumo a um novo pacto social em torno de um desenvolvimento com valorização do trabalho e inclusão dos segmentos sociais historicamente alijados dos benefícios do crescimento econômico nacional.

Se, no final dos anos de 1970 e início da década de 1980, a atuação do sindicalismo brasileiro se mostrou extremamente vigorosa em sua ação conflitiva diante de um quadro de transição democrática, o mesmo não se pode dizer dos anos de 1990. Nesses anos, fatores externos e internos (elevadas taxas de desemprego, redução dos índices de inflação, reestruturação produtiva nas plantas industriais e nas áreas mais dinâmicas do setor de serviços, medidas legais de flexibilização da legislação trabalhista e criminalização de greves, entre outras medidas) deslocaram a ação sindical para um terreno institucional de representação trabalhista expresso, sobretudo, na trajetória da CUT. Diante do contexto adverso do desemprego em patamar elevado e a dificuldade em realizar mobilizações de massa, a ação institucional acabou sendo uma "solução" para os sindicatos permanecerem ativos e, em alguma medida, atuantes na defesa dos interesses dos trabalhadores. Como observa Cardoso (2014, pp.134-135), discorrendo sobre a década de 1990 no Brasil, "o movimento sindical, ou parte importante dele, viu-se na trincheira contra mudanças na Consolidação das

12. A Convenção 158 da OIT foi aprovada em 1982 e dispõe sobre o término da relação de trabalho por iniciativa do empregador, prevendo regras a ser seguidas para justificação do término, procedimentos para desligamento, recursos do empregado contra a demissão, consulta aos representantes sindicais, indenizações e notificação às autoridades. Essa Convenção teve vigência na legislação brasileira entre 5 de janeiro e 20 de novembro de 1996, quando, após Ação Direta de Inconstitucionalidade (Adin) impetrada pela Confederação Nacional do Transporte (CNT) e Confederação Nacional da Indústria (CNI), o governo depositou denúncia do instrumento na sede da oIT, em Genebra. Disponível em: http://www.camara.gov.br/sileg/integras/539004.pdf. Acesso em: 12/8/2017. 
Leis do Trabalho (CLT), elemento crucial de nosso arremedo de estado de bem-estar".

Esses aspectos ajudam a entender a postura de parcelas do sindicalismo brasileiro nos anos de 1990 e, em particular, da Central Única dos Trabalhadores.

Por razões distintas das observadas na década de 1990, as primeiras décadas do século XXI, com os governos do PT, reforçaram a ação institucional do sindicalismo brasileiro $^{13}$. Nesse caso, não mais para "substituir" uma classe que tinha receio de mobilizar-se diante do desemprego, tampouco para tentar manter direitos que estavam sofrendo pressões flexibilizadoras. No novo governo, a participação em instâncias e fóruns tripartites representava, para alguns setores sindicais, em particular aqueles abrigados no interior da Central Única dos Trabalhadores, contribuir na elaboração de um projeto de sociedade mais inclusiva, com mais justiça social e, por isso mesmo, menos desigual. Em outras palavras: a estratégia não era mais defensiva, no sentido de evitar perdas. Aparentemente, tinha como objetivo a ampliação de direitos nas políticas públicas. Uma motivação, portanto, diametralmente oposta àquela vigente na década de 1990. Nesse sentido, a ação sindical nos canais institucionais teve maior incidência na estratégia da CUT, embora todas as demais centrais reconhecidas tenham, em maior ou menor grau, incorporado essa dinâmica.

O fator comum nas ações institucionais do sindicalismo nos anos de 1990 e após 2003 é que, em ambos os casos, os eventuais logros não foram decorrência, tão somente, de ações que mobilizaram os trabalhadores. Foram ações de negociação possibilitadas, por vezes, no segundo período, por relaçôes de proximidade entre a liderança sindical e o gestor do governo, frequentemente um ex-sindicalista.

É importante ressaltar que também ocorreu, em determinadas pautas de reivindicação, a combinação de mobilização da militância com ações de negociação em mesa, aproveitando-se do contexto favorável no governo Lula. Um exemplo que evidencia essa hipótese foi a política de valorização do salário mínimo, uma das medidas mais importantes tomadas pelo governo Lula ${ }^{14}$. De 2004 a 2013, as centrais sindicais, com preponderância da CUT, realizaram sete marchas a Brasília pelo salário mínimo e outras bandeiras, mobilizando milhares de militantes. Esses movimentos não ocorreram contra o governo, ao contrário, mas em oposição aos setores empresariais no Congresso Nacional (e em parte do Executivo) que pressionavam o governo para não levar adiante o projeto de cálculo do salário mínimo com ganho real baseado na reposição da inflação e no desempenho do PIB.

13. Sobre este tema, ver também Carvalho (2014).

14. A fórmula de cálculo do salário mínimo teve início em 2006, combinando a reposição da inflação anual, acrescida de um ganho real com a média do PIB dos dois anos anteriores, e se transforma em lei em 2011. 
A valorização do salário mínimo era demanda sindical e, por atender também aos segmentos não assalariados (aposentados e beneficiários da assistência social), fazia parte, ao mesmo tempo, da agenda do governo. Nesse caso, essas manifestações não colocavam pressão sobre o governo, mas se coadunavam com sua política.

Muito diverso, no entanto, foi o tratamento dispensado a demandas como a redução da jornada de trabalho para quarenta horas semanais sem redução de salário ou o enfrentamento à prática indiscriminada de terceirização. Nesses e em outros casos, um posicionamento do governo favorável à pauta sindical colocaria uma tensão em sua relação com a base de sustentação parlamentar que representava os interesses de setores empresariais da sociedade. Um bom ambiente de diálogo entre sindicalistas e gestores (ex-sindicalistas ou não), nesses casos, não levaria à nova conquista. Entendemos que a ação institucional, embora importante na consolidação de alguns direitos, tem seus limites. Sua superação exigiria lançar mão de outras formas de luta como mecanismo de pressão.

As centrais sindicais, em alguns momentos, tomaram esse caminho. Em 2013, em defesa da pauta da classe trabalhadora ${ }^{15}$, foi realizado, em diversas ocasiões, o Dia Nacional de Luta. No entanto, na maioria das vezes, contando com baixa adesão e sem a sensibilidade política governamental para incorporar tais reivindicações, praticamente não houve avanços naqueles e em outros temas. Da parte da CUT e da СТв, esse dilema entre uma ação de mobilização das bases e uma pressão usando os canais institucionais e/ou os vínculos de proximidade política foi uma constante nesse período.

Assim, a ação sindical nos governos Lula/Dilma combinou mobilização de base e participação em conselhos e negociações de bastidores pela proximidade com membros do governo. Isso se aplica, preponderantemente, à CUT e à CTB mais do que às demais centrais. (Ramalho et al., 2014; Comerford et al., 2014).

A ênfase das centrais sindicais na participação em espaços de representação social deveu-se também à criação e/ou ampliação de conselhos, assim como à realização de conferências nacionais com etapas estaduais e municipais ${ }^{16}$, em todo

15. A partir de 2003, estimulados pelo ambiente tripartite do Fórum Nacional do Trabalho (FNT), as centrais sindicais, cada vez mais, posicionaram-se na busca de consenso em suas principais demandas. De parte da CUT, a construção de unidade das centrais - e também com os movimentos sociais, através da Coordenação dos Movimentos Sociais (CMS) - passou a ser estratégica para exercer sua hegemonia no campo popular e aumentar a capacidade de pressão para conquistas no governo Lula. Daí derivou uma "pauta da classe trabalhadora" que foi o mote das várias marchas e outras mobilizações que as centrais sindicais realizaram conjuntamente. Para aprofundar essa questão, ver Carvalho (2013, pp. 148-164).

16. A Secretaria Geral da Presidência da República (SG-PR) foi o setor responsável, na gestão do presidente Lula e da presidente Dilma, por estabelecer a relação mais direta com os movimentos sociais de modo a ativar as iniciativas de ampliação da esfera pública e incorporar as demandas sociais na agenda do 
o período dos governos Lula/Dilma, que contaram com a participação de amplos setores sindicais.

Conforme já ressaltado, essa participação era parte de uma agenda positiva (não defensiva) de construção de políticas públicas pelo governo, à época, implicada em uma concepção de consolidação de direitos sociais, inscritos desde 1988 na Constituição Federal e nunca encaminhados efetivamente.

\section{Mudanças na organização sindical e outras formas de ação}

O Fórum Nacional do Trabalho (FNT) foi uma das instâncias que mais mobilizou os sindicalistas. Essa iniciativa governamental trouxe, no período, repercussões significativas à ação sindical. É importante nos determos sobre essa instituição tripartite para uma melhor compreensão desse processo de institucionalização sindical.

Criado em 29/07/2003, o FNT encerrou suas atividades em março de 2006, produzindo um relatório que serviu de base à elaboração da proposta de emenda constitucional n. 369, de 2 de março de 2005 (PEC 369/05), e do anteprojeto de lei de relações sindicais (ALRS), com 238 artigos, encaminhado à tramitação no Congresso Nacional na mesma data da PEC. Mais de quinhentas pessoas participaram de 44 reuniões oficiais em Brasília e de diversos encontros preparatórios. Durante esse período, foram realizadas Conferências Estaduais do Trabalho em todas as unidades da Federação. Elas contaram com a participação de mais de 20 mil pessoas ligadas à área sindical e trabalhista, em ciclos de debates, oficinas, seminários e plenárias. Coordenadas pelas delegacias regionais do trabalho (DRTs), as conferências colheram subsídios para a comissão de sistematização do Fórum (Horn, 2005).

A intenção do governo era a de assegurar medidas legais direcionadas ao fortalecimento da organização sindical e, assim, criar as condições para que os sindicatos desempenhassem um papel mais proeminente de representação na negociação coletiva (Horn, 2005).

governo. Para isso, além dos conselhos e das conferências, foram estabelecidas também as mesas de diálogo e de negociação, ampliadas as ouvidorias e realizadas consultas e audiências públicas. Isso significou que, entre 2003 e 2010, foram reformulados os regimentos internos de dezesseis conselhos nacionais, fortalecendo as ações voltadas às políticas públicas, bem como foram criados mais dezenove conselhos nacionais no mesmo período, resultando na existência de 61 conselhos nacionais em 2010, envolvendo a participação de 1.742 pessoas, sendo 785 (45\%) delas representantes do governo e 957 (55\%) representantes da sociedade civil. Em relação às conferências nacionais, foram realizadas 112 de 1941 a 2010, sendo que 21 aconteceram entre 1941 e 1994, 20 de 1995 a 2002 e 71 de 2003 até meados de 2010. A participação da sociedade civil nesses espaços gerou o encaminhamento (e, eventualmente, a aprovação) de projetos de lei em diversas áreas: saúde, meio ambiente, "minorias" (mulheres, negros, juventude, LGBT etc.), desenvolvimento, direitos humanos, entre outras (Almeida, s/d). Ver também Carvalho (2013, pp. 133-148) e Leite Lopes e Heredia (2014). 
O dissenso, no entanto, prevaleceu nas discussões da reforma sindical, tanto na contenda entre trabalhadores e empregadores, quanto entre as centrais sindicais. Assim, as propostas encaminhadas ao Congresso Nacional não tiveram a força política necessária para que fossem levadas adiante e, na Câmara e no Senado, foram apensados diversos projetos ${ }^{17}$, desfigurando o documento original. Todos os grupos sociais que não tiveram seus interesses contemplados na PEC 369/05 e no ALRS reagiram às mudanças propostas e o projeto não foi adiante. Diante desse processo, o governo federal avocou a si a iniciativa de fazer uma "reforma" menos abrangente, contendo três medidas que tiveram o condão de trazer mudanças significativas no modelo corporativo sem transformar, no entanto, sua essência e, ao mesmo tempo, provocou uma inflexão na organização do sindicalismo brasileiro: o reconhecimento legal das centrais sindicais $(11.648 / 08)^{18}$; a portaria $326 / 13^{19}$; e a criação do Conselho de Relações de Trabalho $(\mathrm{CRT})^{20}$. Essas mudanças estavam profundamente

17. Diversas iniciativas do legislativo concorreram com as propostas emanadas do FNT (PEC 369 e ALRS). Entre elas, a PEC 29/2003, de autoria dos deputados Vicentinho (PT-SP) e Maurício Rands (PT-PE), que teve apensada a PEC 121/2003, do deputado Almir Moura (PL-RJ), e foi encaminhada com parecer pela admissibilidade à Comissão de Constituição e Justiça e de Cidadania (CCJC). Outra iniciativa foi tomada pelo deputado Tarcísio Zimmermann (PT-RS) que, diante do impasse da reforma sindical, aproveitou projeto de lei n. 1528 de 1989 (PL 1528/89), ao qual foram apensados outros catorze PLs (propostos por parlamentares de diversos partidos e estados no período entre 1989 e 2007, com vários pls do início da década de 1990), e fez uma redação única, encaminhando o texto à Comissão de Trabalho, de Administração e Serviço Público como um substitutivo ao projeto original.

18. A personalidade das centrais sindicais foi assegurada na lei mediante o art. 2: "Para o exercício das atribuições e prerrogativas a que se refere o inciso II do caput do art. 1 desta lei, a central sindical deverá cumprir os seguintes requisitos: I - filiação de, no mínimo, 100 (cem) sindicatos distribuídos nas 5 (cinco) regiões do País; II - filiação em pelo menos 3 (três) regiões do País de, no mínimo, 20 (vinte) sindicatos em cada uma; III - filiação de sindicatos em, no mínimo, 5 (cinco) setores de atividade econômica; e IV - filiação de sindicatos que representem, no mínimo, 7\% (sete por cento) do total de empregados sindicalizados em âmbito nacional".

19. A portaria $326 / 2013$ substituiu a portaria $186 / 2008$. Ambas tratam do registro de sindicatos no Ministério do Trabalho, definindo extenso trâmite burocrático e uma longa lista de documentos pessoais dos sindicalistas, atas e registros de cartório, que deve ser atualizada após cada eleição sindical, independentemente de haver ou não mudança de seus membros. Tais procedimentos asseguram às entidades o código sindical, documento que permite receber na Caixa Econômica Federal (CEF) a parte da contribuição sindical (imposto) que lhe cabe por lei. É também nesse processo de registro e atualização de dados que os sindicatos indicam ao Ministério para qual Federação, Confederação e Central Sindical deverão ser destinados os recursos do imposto sindical recolhido em sua base de representação.

20. O CRT foi criado através da portaria n. 2.092, de 2/9/2010, para “promover a democratização das relações do trabalho e o tripartismo, o entendimento entre trabalhadores, empregadores e governo federal a respeito de temas relativos às relações do trabalho e à organização sindical e fomentar a negociação coletiva e o diálogo social". É no CRT que as centrais sindicais representativas definem normas para aferição do tamanho de cada uma daquelas entidades (que dá acesso proporcional à fatia de $10 \%$ do total da contribuição sindical). 
imbricadas e tiveram uma ampla repercussão no rearranjo da organização sindical no Brasil. A contribuição sindical (imposto sindical) foi, naquele momento, mantida e as centrais sindicais passaram a contar com $10 \%$ do montante nacional conforme a proporcionalidade da representação segundo os critérios da lei 11.648/08.

De todas as medidas adotadas, o reconhecimento das centrais foi a de maior alcance. Desde a década de 1980, as centrais sindicais já tinham legitimidade política, mas não haviam conquistado personalidade sindical para representar e negociar em nome das entidades a elas filiadas. Em termos práticos, após a lei 11.648, as centrais assumiram o papel que antes era reservado às confederações sindicais (poucas vezes cumprido $^{21}$ ) na cúpula da estrutura sindical, em termos de coordenação das entidades e negociação em instâncias nacionais, embora haja quem argumente que, na nova situação, a reforma favoreceu a centralização de poder em entidades de cúpula. $\mathrm{Na}$ época, diversos especialistas e estudiosos se pronunciaram contrários a aspectos da reforma ou mesmo à totalidade da PEC 369/05 e ao ALRS. O então ministro do TST, Almir Pazzianotto, aponta a interferência do Estado na organização sindical e no financiamento das entidades. Ricardo Antunes, em entrevista ao Correio da Cidadania, e também Andreia Galvão, em entrevista à revista PUC Viva, mencionam a crítica ao "cupulismo" no bojo da reforma (Ladosky, 2009, pp. 232-247). O fato é que a principal disputa sindical ocorreu em eleições e na criação de sindicatos, em grande medida, com o objetivo de angariar maior parcela dos recursos do imposto sindical. Da mesma forma, as centrais sindicais passaram a insistir que seus sindicatos associados atualizassem as informações no Cadastro Nacional de Entidades Sindicais (CNES) informando a filiação para contabilizar na representatividade das centrais. Em outras palavras, é a "maior presença nas entidades sindicais de base" que garante financeiramente a existência da entidade de cúpula, a central sindical.

Em resumo, o resultado final das mudanças na legislação sindical após 2008, ao contrário da intenção inicial de superar o corporativismo estatal, ampliou a participação do Estado na organização sindical. Não mais uma intervenção autoritária, indevida e indesejada pelas entidades sindicais tal como no passado, mas sim, reproduzindo aspectos de um neocorporativismo, discutindo diversos aspectos da organização sindical no então recém-criado Conselho de Relações de Trabalho (CRT), com participação de representantes do estado, de entidades patronais e de sindicalistas das centrais sindicais reconhecidas legalmente (Ramalho et al., 2014).

21. A regra geral de uma falta de coordenação e representação sindical pelas confederações teve algumas exceções: a Confederação Nacional dos Trabalhadores da Agricultura (Contag) e a Confederação Nacional dos Trabalhadores da Indústria (CNTI) no período pré-1964. Feitas essas ressalvas, o verticalismo da estrutura corporativista reservou às confederaçôes um papel de acomodação de dirigentes sindicais em órgãos de cúpula e distanciamento em relação aos sindicatos de base. 
De acordo com dados do Portal do Ministério do Trabalho, essas medidas estimularam o ritmo elevado de pedidos de reconhecimento de entidades sindicais ${ }^{22}$ de trabalhadores - sindicatos, federações, confederações e centrais sindicais - entre 2012 e 2016. Interessante assinalar que em todos os anos do período mais de $80 \%$ dos pedidos de registro de novos sindicatos são de trabalhadores da área urbana, com preponderância do setor público ${ }^{23}$.

Já o Conselho de Relações de Trabalho, criado como desdobramento da tentativa de reforma sindical, também teve a presença de dirigentes das centrais em reuniões mensais, além de calendário ordinário das câmaras bipartites setoriais e de grupos de trabalho que foram formados para discussão de temas específicos.

Há outros exemplos da ação institucional das centrais no período, para além da discussão sindical. As comissões setoriais de competitividade, no âmbito do plano Brasil Maior, contou também com a presença de muitos sindicalistas para debater a política industrial em dezoito setores produtivos. $\mathrm{O}$ resultado mais sensível dessa experiência foi o acordo Inovar-Auto que teve uma contribuição efetiva dos sindicalistas na definição da estratégia de desenvolvimento no setor automotivo (montadoras e autopeças).

De outra parte, em 2010, foi lançada pelo Ministério do Trabalho, a Conferência Nacional do Trabalho Decente com o chamado às representações de trabalhadores e empresários para debater a implantação no país das diretrizes da Organização Internacional do Trabalho (OIT). Envolveu milhares de delegados nas etapas municipal e estadual e teve sua conclusão, com ampla participação em sua fase nacional ${ }^{24}$, em agosto de 2012. Nesse aspecto, um conjunto de medidas legais tomadas ao longo do

22. O portal de relações de trabalho, do Ministério do Trabalho, disponibiliza a informação de que, entre 2012 e 2016, foram protocolados de 530 a 950 pedidos de novos cadastros de sindicatos (patronais e de trabalhadores) por ano. Ou seja, uma média entre 1,4 e 2,6 pedidos/dia (disponível em: http://relacoesdotrabalho.mte.gov.br/pentaho/api/repos/:public:SRT:srt_principal1.xaction/ generatedContent. Acesso em: 15/5/2017). Na verdade, o descompasso entre o ritmo de criação de sindicatos e a taxa de sindicalização é anterior ao reconhecimento das centrais, como evidencia Cardoso (2015, p. 494).

23. Uma explicação plausível para esse fenômeno é que, embora tenha havido o reconhecimento legal de formar entidades sindicais na Constituição de 1988, muitos sindicatos do setor público não formalizaram sua existência legal no Ministério do Trabalho, vindo requerer sua Carta Sindical somente no período mais recente, quando passaram a ter direito ao imposto sindical, bem como a indicar os órgãos de cúpula (federação, confederação e central sindical) para onde deveria ser destinada a parte do imposto arrecadado entre os trabalhadores de sua base.

24. A $1^{\text {a }}$ Conferência Nacional do Trabalho Decente teve início com a realização de 273 conferências preparatórias - 138 municipais, 5 microrregionais, 104 regionais e 26 estaduais - até a etapa nacional, de 8 a 11 de agosto de 2012. De acordo com Laís Abramo, então diretora do escritório da OIT no Brasil, a estimativa foi que 25 mil pessoas participaram desse processo. (Disponível em: http://www. oitbrasil.org.br/node/887. Acesso em: 13/8/2017). 
período fortaleceu ações do Estado de erradicação do trabalho infantil e de combate ao trabalho análogo à escravidão, bem como uma agenda de discussão sobre trabalho da juventude e das mulheres. Assim, esses temas passaram a ter maior relevância nas políticas públicas, nesse período.

A constituição do Conselho de Desenvolvimento Econômico e Social (CDES) no governo Lula, com representantes sindicais, de entidades empresariais e da sociedade civil, sinalizou que a voz dos trabalhadores seria ouvida na definição das estratégias mais gerais de desenvolvimento do país. Segundo relato de Artur Henrique da Silva Santos, então presidente da cuT e conselheiro, foi em uma reunião desse conselho, em 17 de maio de 2007, que surgiu um grupo de trabalho para elaborar um marco das relações de trabalho no setor da cana que, se por um lado, naquele momento, ganhava destaque pelo aumento da produção de combustível a partir do etanol, por outro, também se destacava, negativamente, pelo número de morte de trabalhadores no corte da cana.

Dois anos depois, no dia 30 de junho de 2009, entidades representativas dos trabalhadores do campo, como Contag (Confederação Nacional dos Trabalhadores na Agricultura) e Feraesp (Federação dos Empregados Rurais Assalariados do Estado de São Paulo) assinam, junto com a Secretaria Geral da Presidência e entidades empresariais do setor sucroalcoleiro, o Compromisso Nacional para Aperfeiçoar as Condições de Trabalho na Cana-de-Açúcar. O documento contém cinco cláusulas que estabelecem padrões mínimos de jornada, remuneração, quantidade de cana cortada, condições de trabalho, equipamentos de segurança, alojamentos, alimentação, assistência médica, forma de contratação e respeito à negociação coletiva e ação sindical, entre outros itens (Santos, 2012, p. 56).

Na esteira do Compromisso da Cana, em 2011 foi iniciada a negociação que chegou, em $1^{\circ}$ de março de 2012, ao ato de assinatura do Compromisso Nacional para Aperfeiçoar as Condições de Trabalho na Indústria da Construção. É importante ressaltar que, nesses dois casos, a adesão das empresas a esses acordos é voluntária.

As ações do sindicalismo não se limitaram à ação institucional. Além da realização de várias Marchas e Dia Nacional de Luta pelas centrais, já mencionados, no nível local os sindicatos conduziram greves contra seus empregadores e há casos em que foram arrastados à ação coletiva pela iniciativa grevista autônoma dos trabalhadores, à revelia das organizações sindicais.

Concorreram, favoravelmente, para a ocorrência de um expressivo crescimento do número de greves, a melhoria da situação econômica no período, o mandato de um governo que, apesar das limitações, era mais sensível às demandas dos trabalhadores e, além disso, as condições de trabalho extremamente precárias em algumas áreas do 
país. Greves e ação institucional algumas vezes se retroalimentavam. Nesse sentido, a questão principal que teria levado às tratativas para o chamado Compromisso da Construção, segundo o então presidente da CUT, teriam sido as notícias da greve explosiva, levada a cabo por operários nos canteiros de obra das Hidrelétricas de Jirau e de Santo Antônio (RO), com ônibus incendiados e alojamentos depredados e sem o conhecimento do sindicato local.

Ocorreu um aumento das greves, no período 2004-2015, se comparamos com os anos de 1990, em diversos setores e por todo o país. Apoiados em dados do Dieese, Boito Jr. e Marcelino (2010, p. 331) mencionam a ocorrência de 302 greves em 2004, mantendo ou elevando esse patamar de paralisações ano a ano até chegar a 411 greves em 2008. Tais movimentos envolveram uma média aproximada de 1,5 milhão de grevistas em cada ano, no setor público e privado. Braga (2016, pp. 7273), baseado na mesma fonte, menciona a ocorrência de 462 greves em 2012 e de 1.106 em 2013, um crescimento de $138,4 \%$. O autor observa que as categorias mais mobilizadas têm preponderância do setor industrial, mas a taxa de crescimento das greves no setor de comércio e serviços privados é o que mais chama a atenção em razão da expansão da ação coletiva em setores mais precarizados do mercado de trabalho, "não qualificados ou semiqualificados, sub-remunerados, submetidos a contratos precários de trabalho e mais distantes de certos direitos trabalhistas” (Idem, p. 72), como trabalhadores em turismo, limpeza (garis), segurança, educação, comunicação e, sobretudo, motoristas e cobradores de ônibus urbanos ${ }^{25}$.

De acordo com o Dieese, essas greves atingiram o seu auge ao final do período em tela (2013-2015), quando teriam sido realizadas cerca de duas mil greves em cada um desses anos, conforme o Gráfico 2. A tipologia utilizada por essa instituição para a análise das greves são duas: propositiva ou defensiva. "As greves propositivas propõem novas conquistas ou ampliação das já asseguradas”. Já as greves defensivas "caracterizam-se pela defesa de condições de trabalho vigentes, pelo respeito a condições mínimas de trabalho, saúde e segurança ou contra o descumprimento de direitos estabelecidos em acordo ou legislação" (Dieese, 2017, p. 4).

Mencionamos as "greves selvagens" de trabalhadores da construção civil em obras do PAC, como as Hidrelétricas de Santo Antônio e Jirau. Também tiveram relevância, no período, entre outras, as greves no porto de Suape (Véras de Oliveira, 2013) e na construção dos estádios de futebol para a Copa (Rombaldi, 2014), todas elas

25. Cardoso (2014, pp. 121-122) ao analisar as greves da primeira década do século xxi observa que representaram muito mais "um movimento consolidado e atuante". Dito de outra forma, as greves neste período, seja em número de trabalhadores ou em horas paradas, estiveram muito aquém daquelas que levaram à explosão grevista no final dos anos de 1970 e na década de 1980 . Ver, também, Cardoso (2015) e Noronha (1991). 
GRÁFICO 2

Greves por Reivindicações (2003-2015)

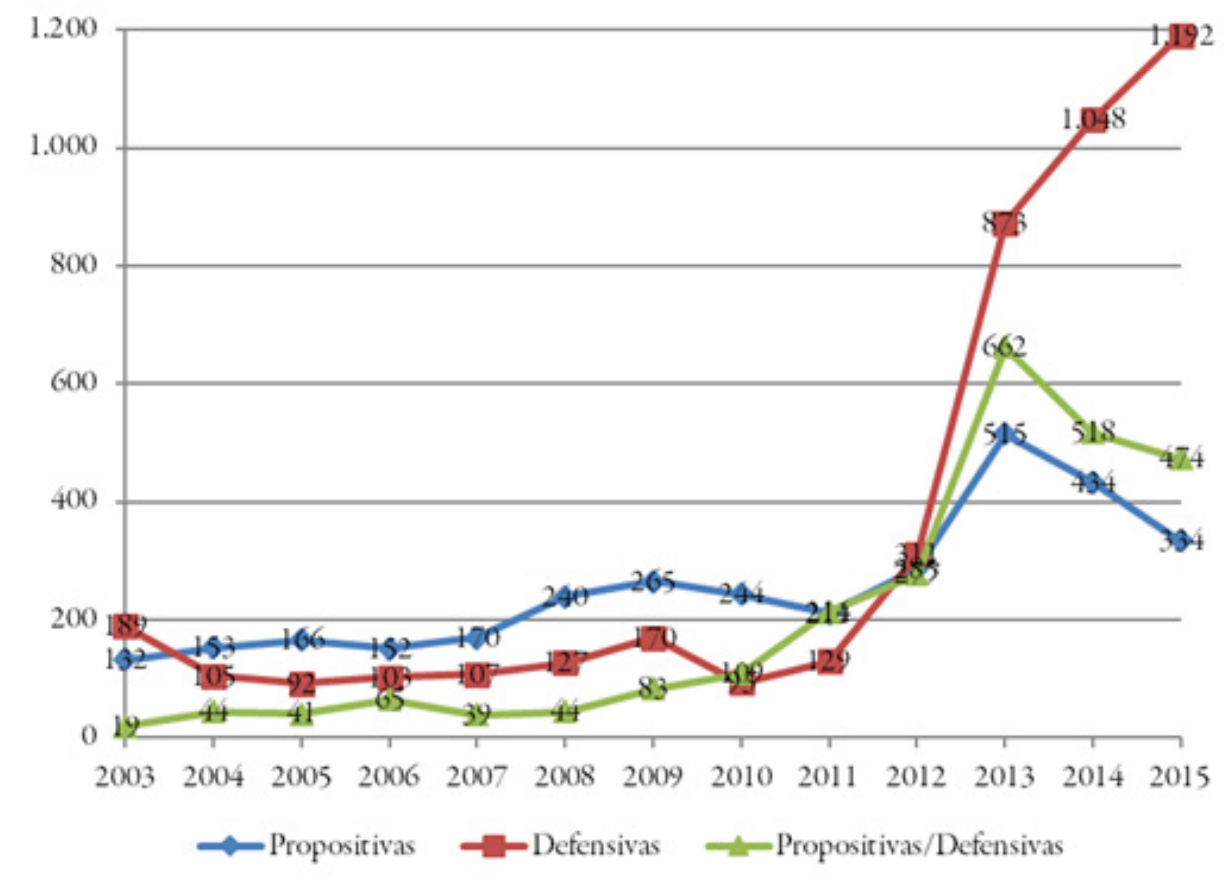

Fonte: Dieese. Sistema de Acompanhamento de Greves (sAG/Dieese). 2016.

com as mesmas características e alheias às orientações das direções sindicais que se mostraram, naquele momento, completamente ausentes do cotidiano dos operários em seus locais de trabalho.

Essas greves, em alguma medida, expressavam a fissura entre os espaços de ação institucional do sindicalismo e o mundo real e precário do trabalho para uma parcela significativa de trabalhadores país afora. Representavam também a fratura no mundo do trabalho entre trabalhadores estáveis e aqueles que são instáveis e excluídos.

Se, de um lado, a participação do movimento sindical nos canais institucionais de representação de interesses representou um espaço de conquista de direitos, de outro, significou uma limitação, uma vez que esse processo, como mostrado neste artigo, acabou por assumir grande relevância na ação do sindicalismo no período diante das ações relacionadas à organização dos trabalhadores.

\section{Considerações finais}

A década de 1980 viu recrudescer as lutas sindicais no ocaso do regime militar. Os trabalhadores se mobilizaram com radicalidade na luta por seus direitos. $\mathrm{Na}$ 
esteira desse processo e como expressão do fim da ditadura militar, foi promulgada a Constituição de 1988 que incorporou parte da agenda de direitos das classes trabalhadoras. Algumas dessas medidas, no entanto, até hoje, não se concretizaram. Uma das razões para que isso não tivesse ocorrido se deve, de um lado, ao contexto de um capitalismo reestruturado sob a égide da financeirização globalizada a exigir um Estado "mínimo" e, de outro, às fraquezas do próprio sindicalismo em nosso país que, afora algumas poucas exceções, não foi capaz de criar uma real organização nos locais de trabalho.

Além disso, o movimento sindical que ressurgiu no final da década de 1970 e início dos anos de 1980 procurou resistir como pôde à onda de precarização que assolou o país na década de 1990. No entanto, a reconfiguração da classe trabalhadora, nesse período, com a flexibilização do trabalho formal e de todas as garantias de proteção laboral com a crescente informalidade, implicou profundas mudanças culturais no mundo do trabalho. As novas gerações incorporaram novos valores que se diferenciavam, em muito, daqueles que se fizeram presente na ação sindical na segunda metade da década de 1970. O distanciamento político-organizativo entre trabalhadores e entidades sindicais, presente na legislação desde as décadas de 1930/40, se aprofunda no contexto do final do século Xx e início do XXI, em função de uma nova etapa de acumulação de capital, da qual emergem inovações tecnológicas e organizacionais que ressignificaram o trabalho e as relações laborais, mudando estruturalmente o universo simbólico de trabalhadores e de dirigentes sindicais. Os primeiros não se reconhecem no discurso das lideranças, incapazes de traduzir em demandas os novos anseios das classes trabalhadoras.

As contradições que permearam os governos Lula e Dilma se verificaram também no sindicalismo que lhes deu base de apoio social. Entendemos que esses governos possibilitaram uma agenda trabalhista que, mesmo com as contradições e limites mencionados neste artigo, fortaleceu a ação do sindicalismo-CUT em suas bases sociais, justificando assim que a direção dessa central sindical tivesse forte argumento para promover a defesa dos governos do PT junto aos seus sindicatos, mesmo quando o executivo se colocou contrário às suas demandas como, por exemplo, na questão da redução da jornada de trabalho.

Essa seria uma das razões pelas quais ocorreu um investimento político muito grande nas chamadas ações institucionais e, de modo geral, não contrárias ao governo federal, mas na tentativa de que este tomasse posição em defesa de um "projeto trabalhista”. Essa postura enredou o sindicalismo-CUT em uma lógica de interação com as iniciativas do governo que o afastou de outras demandas e agendas que teriam uma correspondência mais imediata com o cotidiano das classes trabalhadoras, cujo perfil e expectativas - sobretudo suas experiências diante da desregulamentação 
neoliberal da proteção social sobre o trabalho desde a década de 1990 -, estão longe da classe que se forjou nas lutas sindicais da década de 1980. Desse modo, a ação institucional e os logros que eventualmente ocorreram de uma relação próxima com o governo nem sempre "dialogava" ou mantinha algum elo com as expectativas dos trabalhadores. $\mathrm{O}$ descompasso entre conquistas sociais, com base em decretos ou resultados de mesa de negociações, e os movimentos de "greves selvagens" nos setores mais precários do mercado de trabalho, por exemplo, ilustrariam um descompasso entre sindicatos e trabalhadores em determinados setores.

Em meio a esses movimentos contraditórios, nesse período é que aparecem os sinais de crise do sindicalismo-CUT, bem como dos setores sociais que apoiavam esse projeto: os sindicalistas falavam de um lugar - os compromissos de um projeto sindical que previa apoio aos governos do PT e que seriam também o projeto histórico da central - sem se conectar com o outro espaço: o dos trabalhadores. Em parte, porque foram colocadas novas demandas e desafios até então inéditos para a CUT e o conjunto do sindicalismo - nas últimas décadas - e, em parte, devido às transformações no mundo do trabalho e, em particular, nos locais de produção e serviços, bem como à falta de sintonia de setores sindicais com as mudanças estruturais que reconfiguraram o perfil das classes trabalhadoras.

No caso específico da CUT, o papel desempenhado pela temática da organização nos locais de trabalho no seu projeto estratégico é um exemplo, entre outros. Apenas a título de ilustração, no $12^{\circ}$ Concut (2015) foi tirada a seguinte resolução: "promover um amplo debate sobre oLt [organização por local de trabalho], com foco nas experiências já existentes no setor público e privado, com o objetivo de construir, com base nessas experiências, diretrizes para a ação da CUT nesta área" (Concut, 2015, p. 87).

Considerando o grau de dificuldades de organização no interior das empresas públicas e privadas, as Comissões Internas de Prevenção de Acidentes (Cipas) se constituíram em principal meio de organização dos trabalhadores nos locais de trabalho. Para além dessas, destacam-se como as experiências mais conhecidas e consolidadas no sindicalismo-CUT as comissões de fábrica e os comitês sindicais de empresa (CSE) dos metalúrgicos do ABC; o sistema único de representação (SUR) dos químicos do ABC; e, no setor público, os representantes de escola na Apeoesp e os representantes sindicais de unidade (RSU) entre os servidores municipais de São Paulo. Essas poucas experiências exitosas convivem com outras mais esporádicas e demonstram o quanto o sindicato no Brasil ainda está distante dos trabalhadores nos locais de trabalho.

Diante da grave crise política e econômica que se instaurou no país nos últimos anos e que culminou com o impeachment da presidente Dilma Rousseff em 2016, 
o sindicalismo terá que refazer sua estratégia se quiser ter alguma relevância social e política no cenário nacional ${ }^{26}$. E, certamente, essa "reinvenção" do sindicalismo, mesmo sem deixar ao largo outras esferas de atuação, terá que passar por um forte enraizamento nos locais de trabalho.

Quarenta anos após a onda grevista que sacudiu o país em 1978 e que foi fundamental, naquele momento, para a redemocratização da sociedade brasileira e para a conquista de direitos do mundo do trabalho, estamos assistindo a um desmonte, sem precedentes, dos direitos dos trabalhadores. Diante dessa nova situação, a estratégia sindical terá que ser modificada. Em outras palavras, aos sindicatos restou a possibilidade de envidar esforços em diferentes áreas para minimizar os efeitos danosos e perversos dessa regressão de direitos.

Assim, o desafio do sindicalismo é o de se conectar a um projeto de sociedade que vá ao encontro dos anseios e desejos dos trabalhadores do século Xxi, cujo perfil precisa ser conhecido, considerando a sua heterogeneidade e as novas formas de trabalho. Esse não é um caminho fácil. Haverá muitos percalços, avanços e retrocessos. Isso porque essa crise não está afetando apenas a instituição sindical e é consequência, tanto da crise do trabalho que permeia a sociedade contemporânea, quanto de uma crise de representação da instituição sindical. Além disso, essa dinâmica tem uma dimensão que é social, política e econômica.

Em resumo, em que medida a experiência desses últimos quarenta anos, no âmbito do trabalho, trará consequências para a instituição sindical? O sindicalismo terá condições de se renovar, a despeito das transformações na sociedade brasileira, em geral, e do mundo do trabalho, em particular? Será possível se reinventar? Terão os sindicatos capacidade de recuperar sua relevância em relação às classes trabalhadoras? Essas são, pois, questões desafiadoras à ação sindical no Brasil no próximo período.

\section{Referências Bibliográficas}

Aвramo, Laís Wendel. (1999), O resgate da dignidade: greve metalúrgica e subjetividade operária. Campinas, Editora da Unicamp.

AlmeidA, Gerson. (s/d), "Participação social no governo federal”. Disponível em: conselho.saude.gov.br/web_confmundial/docs/painel_3/apres_gersonluiz.ppt. Acesso em: 13/8/2017.

AssumpÇão, Luiz Felipe Monsores de. (2015), "Evolução do número de sindicatos e a crise do sindicalismo brasileiro: uma relação necessária?”. Trabalho apresentado no XVII Congresso Brasileiro de Sociologia, Porto Alegre, 20-23 jul.

26. Ainda é incerta, no momento em que se escreve este artigo (agosto de 2017), a repercussão que o fim da contribuição sindical compulsória dos trabalhadores terá sobre as entidades sindicais. 
Borto JR., Armando. (2012), “As bases políticas do neodesenvolvimentismo”. Trabalho apresentado no Fórum Econômico da FGv, São Paulo.

\& Marcelino, Paula. (2010), "O sindicalismo deixou a crise para trás? Um novo ciclo de greves na década de 2000”. Caderno CRH, 23 (59): 323-338.

BrAGA, Ruy. (2016), “Terra em transe: o fim do lulismo e o retorno da luta de classes". In: SinGER, André \& Loureiro, Isabel (orgs.), As contradições do lulismo: a que ponto chegamos? São Paulo, Boitempo.

\& Santana, Marco Aurélio. (2015), "Dinâmicas da ação coletiva no Brasil contemporâneo: encontros e desencontros entre o sindicalismo e a juventude trabalhadora”. Caderno CRH, 28 (75): 529-544.

Cardoso, Adalberto. (2014), “Sindicatos no Brasil: passado, presente e futuro”. In: CaTTANI, Antônio David (org.). Trabalho: Horizonte 2021. Porto Alegre, Escritos Editora.

. (2015), “Dimensões da crise do sindicalismo brasileiro". Caderno CRH, 28 (75): 493-510.

Carvalho, Fernanda Forte de. (2013), Os dilemas da CUT no início do século XXI: rumo a uma nova institucionalização sindical? Coimbra, tese de doutorado, Faculdade de Economia da Universidade de Coimbra.

Carvalho, Guilherme. (2014), A representação da CUT nos governos Lula (2003-2010). São Paulo, Editora da Unesp.

Concut. (2015), Caderno de Resoluções do $12^{\circ}$ Congresso Nacional da CUT. São Paulo, CUt.

COMERFord, John et al. (2014), “o mundo da participação e os movimentos rurais: entre mobilizações, espaços de interlocução e gabinetes”. In: Lopes, José Sergio Leite \& Heredia, Beatriz Maria Alasia de (orgs.). Movimentos sociais e esfera pública: o mundo da participação: burocracias, confrontos, apendizados inesperados. Rio de Janeiro, СВAE.

DieEse. (2012), A situação do trabalho no Brasil na primeira década dos anos 2000. São Paulo, Departamento Intersindical de Estatística e Estudos Socioeconômicos.

. (2016), "Balanço das negociações dos reajustes salariais de 2015”. Estudos e Pesquisas, 80. São Paulo, Departamento Intersindical de Estatística e Estudos Socioeconômicos. . (2017), "Balanço das greves de 2016”. Estudos e Pesquisas, 84. São Paulo, Departamento Intersindical de Estatística e Estudos Socioeconômicos.

Dobrusin, Bruno. (2017), Las centrales sindicales ante gobiernos neodesarrollistas: un análisis a partir de las politicas de salario minimo en Argentina (2003-2011) y Brasil (2002-2010). Buenos Aires, tese de doutorado, Universidad Buenos Aires.

Fortes, Alexandre \& French, John. (2012), “A 'Era Lula', as eleições presidenciais de 2010 e os desafios do pós-liberalismo". Tempo Social, 24 (1): 201-228.

Galvão, Andréia \& Marcelino, Paula. (2017), "O sindicalismo brasileiro diante do golpe”. Trabalho apresentado no XV Encontro Nacional da ABET. Rio de Janeiro, set.

Galvão, Andréia et al. (2015), As bases sociais das novas centrais sindicais brasileiras. Curitiba, Appris. 
Gumbrell-McCormick, Rebecca \& Hyman, Richard. (2013), Trade unions in Western Europe: hard times, hard choices. Oxford, Oxford Universty Press.

Hyman, Richard. (2001), Understanding European trade unionism: between market, class \& society. Londres, Sage.

\& Gumbrell-McCormick, R. (2010), “Trade unions, politics and parties: is a new configuration possible?” Transfer, 16 (3): 315-331.

Horn, Carlos Henrique. (2005), "Reflexões sobre consenso e dissenso na reforma sindical". Trabalho apresentado no xxix Encontro Anual da Anpocs, Caxambu.

Krein, Dari et al. (2012), “Trabalho no governo Lula: avanços e contradições”. Texto para discussão, n. 201. Campinas, IE/Unicamp.

Ladosky, Mario Henrique Guedes. (2009), A cUT no governo Lula: da defesa da liberdade e autonomia’ à reforma sindical inconclusa. São Paulo, tese de doutorado, Programa de Pós-graduação em Sociologia do Departamento de Sociologia da Faculdade de Filosofia, Letras e Ciências Humanas da Universidade de São Paulo.

et al. (2014), "A questão trabalhista e os desafios da ação sindical nos anos 2000". In: Véras de OliveIra, Roberto et al. (orgs.). O Sindicalismo na era Lula: paradoxos, perspectivas e olhares. Belo Horizonte, Fino Traço.

Leite Lopes, José Sergio \& Heredia, Beatriz Maria Alasia de (orgs.). (2014), Movimentos sociais e esfera pública: o mundo da participação: burocracias, confrontos, aprendizados inesperados. Rio de Janeiro, СваE.

Nogueira, Arnaldo Mazzei. (2006), “Um balanço das relações de trabalho no setor público brasileiro na transição do governo FHC pra o governo Lula”. Informações Fipe, 11 (06): 16-22.

Noronha, Eduardo. (1991), “A expansão das greves na década de 80”. In: Boito JR., Armando. $O$ sindicalismo brasileiro nos anos 80. São Paulo, Paz e Terra.

Ramalho, José Ricardo et al. (2014), “O movimento sindical urbano no exercício da participação". In: Leite Lopes, José Sergio \& Heredia, Beatriz Maria Alasia de (orgs.). Movimentos sociais e esfera pública: o mundo da participação: burocracias, confrontos, aprendizados inesperados. Rio de Janeiro, СвAE.

Ramos, Vanessa. (2011), “Política agrária do governo Lula valorizou o agronegócio”. Entrevista com Ariovaldo Umbelino. Disponível em: http://www.cartacapital.com.br/politica/ politica-agraria-do-governo-lula-valorizou-o-agronegocio/.

Rodrigues, Iram Jácome. (2011), Sindicalismo e política: a trajetória da CUT (1983-1993). São Paulo, LTr.

\& Ramalho, José Ricardo. (2014), "Novas configurações do sindicalismo no Brasil? Uma análise a partir do perfil dos trabalhadores sindicalizados”. Contemporânea - Revista de Sociologia da UFSCar, 4 (2): 381-403.

Rodrigues, Iram Jácome \& Ladosky, Mario Henrique. (2015), "Paradoxos do sindicalismo brasileiro: a CUT e os trabalhadores rurais". Lua Nova, 95: 87-142. 
Rodrigues, Leôncio Martins. (1999), Destino do sindicalismo. São Paulo, Edusp.

\& CARdoso, Adalberto Moreira. (1993), Força Sindical: uma análise sociopolitica. São Paulo, Paz e Terra.

Rombaldi, Maurício. (2014), “A Copa de 2014 e os trabalhadores da construção: estratégias globais, mobilizações locais”. Revista da ABET, 13 (2).

Santos, Artur Henrique da Silva. (2012), CUT: um olhar de 2006 a 2012. Campinas, Sinergia.

Singer, André. (2012), Os sentidos do lulismo: reforma gradual e pacto conservador. São Paulo, Companhia das Letras.

Trópia, Patrícia. (2009), Força Sindical: política e ideologia no sindicalismo brasileiro. São Paulo, Expressão Popular.

VÉras de OliveIra, Roberto. (2011), Sindicalismo e democracia no Brasil: do novo sindicalismo ao sindicato cidadão. São Paulo, Annablume.

. (2013), "Suape em construção, peões em luta: o novo desenvolvimento e os conflitos do trabalho". Caderno CRH, 26 (68): 233-252.

et al. (orgs.). (2014), O sindicalismo na era Lula: paradoxos, perspectivas e olhares. Belo Horizonte, Fino Traço.

\section{Resumo}

A cut e o sindicalismo brasileiro nos anos recentes: limites e possibilidades

Este artigo analisa a ação do sindicalismo brasileiro e, em especial, da Central Única dos Trabalhadores, nos governos Lula e Dilma. O nosso argumento é que uma parcela significativa do sindicalismo e, em particular, a CUT, diante das novas condições vividas pelo Brasil, naquele momento, não conseguiu coadunar a atuação institucional com uma maior organização dos trabalhadores nos locais de trabalho.

Palavras-chave: Brasil; Sindicalismo; Trabalhadores; Central Única dos Trabalhadores; Governos Lula e Dilma.

\section{Abstract}

The cut and the Brazilian trade unionism in the recent years: limits and possibilities

The present paper analyses Brazilian unionism action, with focus on the main union centre in Brazil, the cut (Unified Workers' Central), during Lula's and Dilma's governments. Our argumentation is that a significant part of the unionism, and the CUT in particular, upon new 
conditions lived in Brazil in that moment, was unable to join its institutional acting with an increase of labour organization in the working places.

Keywords: Brazil; Trade unionism; Workers; Unified Workers' Central; Lula's and Dilma's governments.

Texto recebido em 19/9/2017 e aprovado em 16/10/2017. Dor: 10.11606/0103-2070. ts.2018.138079.

MARIO HENRIQUe GUEDES LADOSKy é professor doutor da Unidade Acadêmica de Ciências Sociais da Universidade Federal de Campina Grande (UACs/ufCg) e do Programa de Pós-graduação em Ciências Sociais (PPGCS/UFCG).E-mail: mhladosky@gmail.com.

IRAM JÁCOME RODRIGUES é professor associado (livre-docente) do Departamento de Economia da Universidade de São Paulo e do Programa de Pós-graduação em Sociologia da Universidade de São Paulo (PPGS-USP) e pesquisador do CNPq. E-mail: iramjrodrigues@gmail.com.

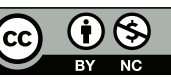

